\title{
(Re)imagining success through photovoice: Highlighting a research and teaching strategy that could be useful in physics/STEM education
}

\author{
L. Trenton S. Marsh \\ Department of Learning Sciences and Educational Research, University of Central Florida, \\ 4000 Central Florida Boulevard, Orlando, FL 32816
}

\begin{abstract}
Students, especially those facing multiple marginalization, often have limited exposure to opportunities to formulate and express their opinions and interests. This article highlights the use of photovoice, a participatory qualitative research method that enables participants to capture and communicate their perceptions, reality, and social landscapes using the power of visual imagery. Working with minoritized students attending a public charter middle school, the photovoice project reveals how students (re)imagine success and how these conceptualizations mirror a preferred sociocultural learning style. A style which is in tension to the analytic approach offered in their charter school. The photovoice method could be useful in the physics/STEM education research community, particularly to reshape how "bridge programs" that prepare minoritized students to enter STEM degree programs, might (re)imagine success by empowering participants in those programs to share what success looks like to them.
\end{abstract}

2020 PERC Proceedings edited by Wolf, Bennett, and Frank; Peer-reviewed, doi.org/10.1119/perc.2020.pr.Marsh

Published by the American Association of Physics Teachers under a Creative Commons Attribution 4.0 license. Further distribution must maintain the cover page and attribution to the article's authors. 


\section{INTRODUCTION}

The fundamental purpose of success in school in the United States has been repeatedly debated. Success in school centers on what counts as knowledge, how will knowledge be ordered, where will the dissemination take place, and to which students it will be distributed $[1,2]$. Success in school can also be anchored in students' learning styles, which seem to be socioculturally preferred and not biologically determined [3]. Nearly 50 years ago, sociologist Rosalie Cohen [4] identified that the traditional classroom in America operationalizes generic requirements for success in school that derive from an analytic cognitive approach to learning. Signs of this learning style were found in the requirements that the student learn to "sit increasingly long periods of time, to concentrate alone on impersonal learning stimuli, and to observe and value organized time-allotment schedules" [4] (p. 829). However, the analytic approach is suboptimal for minoritized students who prefer relational and communal learning styles [5]. Relational learners are more interested in people, are motivated to acquire knowledge that can be applied to ameliorate social problems and are aware of their social contexts [3]. Similarly, communal learners' value cooperative learning [6]. Despite the cultural mismatch between minoritized and White students [7] much of the classroom learning style in American classrooms has maintained the analytic approach.

Moreover, teachers often espouse a ubiquitous, colorneutral ideal of success couched in dominant achievement ideology and meritocracy. That is, a student's success in school is attributed to assumed capabilities to work hard and exhibit what Duckworth, Peterson, and Matthews [8] refer to as "grit" toward academic achievement which can serve as the crucial link to long-term goals of obtaining the American Dream. This race-neutral frame allows Whites to be unconcerned about discriminatory and racist policies across institutions, including those within schools, in America that (re)produce inequities [9]. Yet these neutral ideals are void of minoritized students' historical and sociocultural contexts, as well as their voice. But how do multiplymarginalized students of color who may not closely reflect a middle-class milieu make meaning of success in school, amid a learning environment that privileges White interests, values, experiences, and beliefs [10]? The purpose of this paper is three-fold: (1) explore how Black and Latinx students attending a high-achieving public charter school conceptualize success using photovoice (defined in Sec. II.D.) (2) briefly compare students' conceptualization of success to that of the schoolwide framing and (3) describe how the photovoice method could be useful in the physics education research community.

\section{METHODOLGY}

\section{A. Guiding Frameworks}

The work is guided by photovoice [11,12], a participatory research method that enables participants to capture and communicate their perceptions, reality, and social landscapes using the power of visual imagery. Rooted in the Freirean approach to critical, emancipatory education [13], photovoice, like Freire's praxis, stresses education is a social practice which is a collective construction [14]. Photovoice is also a decolonizing method in research because it aims to dismantle and address power dynamics in research between participants and researchers. Here, decolonizing is both structural and relational. Structurally, my research agenda is about revising the research process, specifically whose voice matters and is considered valuable. And relationally, as a researcher, I aim to exhibit humility and appreciation for participants' local knowledge and lived experience.

Youth-participatory action research (YPAR) also guides this study. In part due to their lack of experience, youth are oftentimes not provided a voice regarding decision-making. YPAR provides youth with a platform for exploring issues that are important to them and their communities $[15,16]$. YPAR is aligned with the tenets of community-based participatory research [17], in which participants are given a voice in the research process [16]. Individuals who are impacted by the research being conducted are involved in the research process to leverage their localized knowledge [17]. Utilizing a YPAR approach, youth are empowered throughout the entire research to choose topics that are important to them and are also involved with data collection and eventual solution implementation $[15,16,18]$.

\section{B. Research Site}

I draw on data from a larger, single site situated ethnographic study [19]. The analysis reported here is part of a larger qualitative study, conducted over the 2015-2016 academic school year in an urban public charter middle school, with a discipline-focused approach to schooling as they are predicated on communicating high-expectations and personal responsibility that I will refer to as Metropolitan City Charter Academy (MCCA). Across the U.S., disciplinefocused approach schools have been promulgated as a model that closes "achievement gap" [20,21] between lower socioeconomic Black and Latinx students and their upper middle class, White and East Asian peers. To understand students' experiences, I moved into the community of MCCA. In that way, I sought not only to reduce the power differentials between myself as a researcher and my participants [22] but also to avoid being an outsider who daily retreated back to a home locale away from the context, without acknowledging the local knowledge and appreciating the community wealth [23]. Founded in 2004 as 
the first school of a larger charter management organization, the Chief Executive Officer referred to MCCA as the "gold standard" of schooling success because it outperformed its network, regional, and neighborhood peer schools in Math and English Language Arts (ELA) assessment scores [24]. MCCA's mission statement is "to create citizen scholars," and the school motto is: "Hard work is all you need to succeed at MCCA, college, and beyond."

\section{Participants}

While the larger study included students, caregivers of students, and teachers, the focus of this paper is my time with ten Black and Latinx students in the seventh and eighth grade and my observations of their respective classrooms. The students were identified after my making a request of every seventh and eighth grade teacher identify students whom they thought were "ideal" or "at-risk" in the school. Teachers were also asked to write at least one sentence explaining why a student was being identified with the respective label. In addition to identifying students to recruit into the project, the teacher-generated lists and rationales also allowed me to begin to explore teachers' beliefs about MCCA students, including how teachers define and recognize success at MCCA. Seventeen teachers responded, and based on their input, seven boys and three girls were identified and after permissions were granted, opted into the study. Due to length restrictions I focus on two students, one identified as "ideal" and the other as "at-risk" and their photos that are representative of how the ten students conceptualized success at MCCA.

\section{Photovoice: Data collection and analysis procedures}

The collected data for this paper is in the form of photovoice. Photovoice is a participatory qualitative method that entrusts research participants, who are community members, with cameras and encourages them to document their social landscapes through photography $[11,12]$, and participate in the codifying. After initial interviews with student participants, each were given a new digital camera and informed to take pictures based on the photovoice prompt: "what you think success is and/or what it means to you." Each camera was accompanied by an instruction sheet that listed "Picture 1 to Picture 10" with blank lines for picture description. Students were also directed to write at least one sentence as to why the captured images represented success. Students were given seven days to capture pictures and were informed to ask for permission if taking pictures inside of the school or of individuals.

\section{One-on-one interviews}

Prior to receiving students' digital cameras so I could download their images, I asked students to identify on the worksheet their favorite picture. Adapted from researchers
Wang, Burris, and Powers' [12] SHOWed Approach, which asks photovoice participants five questions about their photos, I met individually with each student to conduct a recorded, open-ended interview. During one-on-one interviews, students were able to see their images on an iPad screen. Students were asked to describe in detail why each image depicted success. As students attended to each captured photograph, I also assessed their written response to see if there were any conflict between their spoken and written text. At the conclusion of the interview, students were given a $5 \times 7$ color printout of their previously articulated favorite photograph.

\section{Focus groups}

Student participants' images were also reviewed during a tape-recorded focus group session with another student who participated in the photovoice project. Due to scheduling limitations and space restrictions in the school, participants were paired by grade-level. That is, seventh grade participants were matched with another seventhgrader, and eighth with eighth. I also tried to pair participants by identified gender and teacher-identified labels: "ideal" with "ideal" and "at-risk" with "at-risk."

During student focus groups, I listened to how students presented their pictures to fellow students, offering rationales for the images, as well as responding to peer queries. This provided an opportunity to see if there was any consensus or discrepancy of language or meaning amongst students. When students had similar images to conceptualize success, they were asked to consider what a larger theme could be. For instance, when I paired Felipe and Patrick together, eighth graders who were both labeled "at-risk" by their teachers due to being held back, they both captured images of basketball-related activities. For Felipe, his image was of an empty outside basketball court. He shared during the focus group, "I play basketball to take my mind off. This [playing basketball] is stress relief." He continued, "When I don't do good here [at MCCA], I go to the basketball court and play." Patrick had a similar rationale for his captured image of basketball hall of famer, Michael Jordan. He said the image is part of a larger process that he used to motivate himself every morning before leaving for school, "I tell myself just take one step at a time and keep moving forward, then I go to school. If you take a shot once in a while, you're going to make your shot. And if you keep shooting, shooting, and shooting that's when you're going to start getting good and you're making progress." Collectively, they agreed to define their images of success to be representations of preventative strategies or activities to overcome adversity. Subsequently, "survival methods," became one of the emergent themes based on students' images and narratives of success. 


\section{FINDINGS}

The photovoice prompt, "What you think success is and/or what it means to you?" yielded 74 images from nine students. Eighty percent of the images represented four emergent themes of success: Human Connection, Educative Experiences, Original Compositions, and Survival Methods. I will address two in this paper: a) Human Connection and b) Original Compositions. Below, I highlight two student participants and their exemplar images and offer explanations about the images in students' words. I also contextualize each student based on their teacher identified label, using teacher quotations.

\section{A. Participant Themes and Conceptualization of Success}

\section{Niyatt, $7^{\text {th }}$ grade, identified as "ideal"}

One theme was Human Connection, and I will tell you about this theme through the example of Niyatt and one of her photos. Niyatt was a very quiet seventh grader. Aside from her stature, as she was one of the shortest female students attending MCCA, she was identified by her hijab. Niyatt was one of a dozen Muslim female students in the school who, for religious purposes, cover their head. Niyatt was also first-generation American, as both her parents were born in Western Africa. On the teacher survey, she was described as "incredibly organized and eager to gain new information." One teacher also indicated she "works really hard" and is "very focused and does not allow herself to be distracted by others," while "complet[ing] all of her work." Another teacher offered Niyatt "demonstrat[es] respect and curiosity in the classroom and embodies a calm example of dedication to education."

When Niyatt shared images about what success meant to her, many of her pictures, like those of her peers, represented family, friends, and community markers. Her face lit up when she pointed to her cousin on her bike playing at the local park near the school. "That's the park. It [the park] allows people to come together and make friends." As captured (see Img. 1), Niyatt took a picture of her mother and father, a couple who, in her eyes, represented a unit of Black love that supported each other. When describing her image, she says:

That is family. I thought family was successful because it shows how they are able to commit and stay together and taking care of each other which could be simply successful for family.

While Niyatt is identified as "ideal" by teachers due to her ability to excel within MCCA's analytic learning environment, her revelation about human connection is an important point. Her images and descriptions emphasize inter-human, personal encounters, traits of communal learning. Yet, based on my observations of classrooms, teachers at MCCA rarely positively incorporated families or the broader neighborhood in the framing of success. Rather, when the local community was referenced, it was in a matter of competition and a deficit-orientation, specifically how MCCA was outperforming neighborhood schools in ELA and Math.

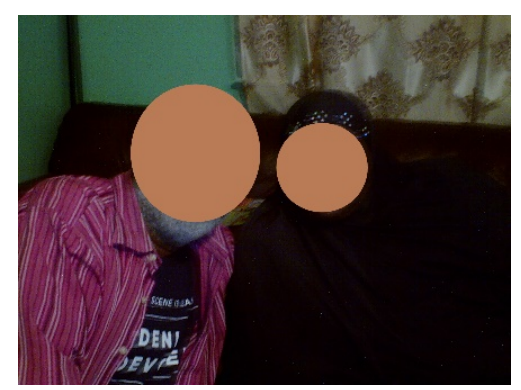

IMAGE 1. Black Love

\section{Mateo, $7^{\text {th }}$ grade, labeled as "at-risk"}

Another theme was Original Compositions, and I will tell you about this theme through the example of Mateo and one of his photos. Mateo, too, is in the seventh grade. However, unlike Niyatt, he has been identified by his teachers as an "at-risk" student at MCCA. Mateo was described by his seventh-grade teachers as "extremely disrespectful," "doesn't care about [his] education," "immature," and "uninvested in [MCCA] culture."

However, in interviews, teachers also described Mateo's academic prowess as he earned a near perfect score on the State exam. He was "smart," had "natural ability" and "intelligence," teachers reflected. Despite this academic potential, Mateo did not have schooling success at MCCA. As one teacher confided, "Raw intelligence does not help you at MCCA, like it might at other schools." Of Mateo's seven classes, he passed only two classes with percentages of at least 70 percent. In an interview, his reading teacher confided, "[I'd] hate to see his potential plateau when [he] is only twelve, thirteen."

But despite his teachers mixed reviews concerning his academics at MCCA, Mateo had a different attitude concerning success. Like his peers who participated in the photovoice project, Mateo reimagined success to encompass creative pursuits. Mateo's picture (see Img. 2) is a representative photo of the original compositions that were captured by students. When describing his hand drawn image, he says:

It's success in its own way. You don't have to be like everyone else to be famous or to even be successful. 


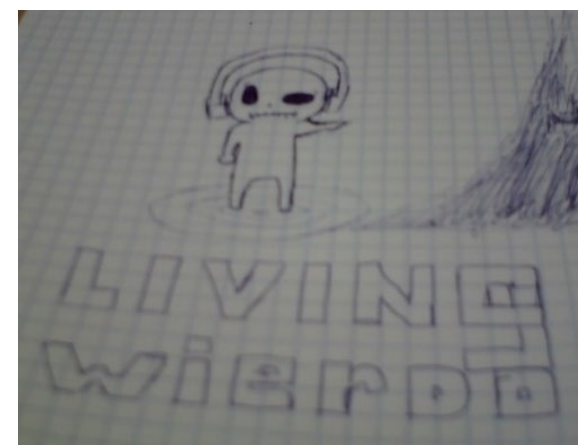

IMAGE 2. Living Weirdo

Students took pictures of handwritten designs and sculptures, as well as images of favorite literary works, poetry and even production equipment for music and cinematography. From their photographs and descriptions, the students identified a variety of stimulation and hands-on activities as success. Collectively these activities could be supplemented into the school, fostering a relational learning environment. However, based on my observations even the spaces where students were supposed to have hands-on learning and commune with others (e.g., theatre, music and gym) these spaces offered little room or value in students being heard and creating as these classes were not highly regarded for closing the purported "achievement gap."

Schools foster many of the dominant achievement and meritocracy norms embodying hidden messages that legitimize and privilege White interests, values, experiences, and beliefs that students experience in classrooms [10]. For working-class students of color this may translate into entering schooling spaces seeped in individualism and competition as opposed to community-centrism. Metropolitan City Charter Academy's approach to schooling reifies a sociocultural oppressive context created for educating lower-income minoritized students. However, as evidenced from the images, students are resisting the academic and behavioral norms institutionalized by the school in how they make meaning of success outside school walls. Students' images symbolize essential psychological nutriments [25], which serve to nourish and sustain students' healthy sociocultural development, growth, and integrity toward full humanity.

\section{IMPLICATIONS}

Young people, especially those facing multiple marginalization, often have limited exposure to opportunities to formulate and express their opinions and interests [26]. This study provides evidence of how photovoice can be used in a school setting to learn from and uplift youth. Youth were provided an authentic space to exercise their visual voice and co-create knowledge concerning their conceptualization of success, which revealed a desire for relational and communal learning styles.

The findings from a photovoice project can also be used in a physics education research community. For example, there are several types of "bridge programs" that prepare minoritized students to enter STEM degree programs, but the program's definitions of success are often linked to acceptance and degree completion, absent of students' voice. As opposed to the traditional "banking system" of education [13], which assumes students are empty vessels in need of information that can only be deposited by a teacher, photovoice as a method would position participants as cocreators of the object of knowledge in those programs to share what success looks like to them. Perhaps it is relational and communal learning. Photovoice can be used as a reflexive tool by programs to ensure students' lived experiences and localized funds of knowledge [27] are embedded into the larger bridge program. For example, a prompt could offer first year students an opportunity to take images about the genesis of their interest in STEM. Further, the prompt could ask students to only consider their neighborhoods/local communities. As I have shared elsewhere [28], as a pedagogical tool, photovoice could also enable teachers to have a more thorough, yet nuanced understanding about their students which can shed additional light to the assets (or challenges) that may exist and impact their transition within a bridge program. Here, teachers would have to be open to students' words, experiences, and for some, imaginations, even if it challenges their viewpoints. Teachers might be ignorant of the dominant achievement ideology of "hard work" as well as grit ideology that undergirds a deficit ideology about students and their families and ignores structural impediments which are often culturally and racially biased and is girded in institutional racism. Creating affirming STEM spaces for multiply-marginalized students to visually identify and furnish photographs that can help STEM teachers understand their interpretations of a situation or opportunity has the potential to stimulate critical reflection not only that can benefit students, but also contribute to the collective construction of STEM-related education.

\section{ACKNOWLEDGMENTS}

Thank you to Dimitri Dounas-Frazer, Jacquelyn J. Chini, and Gina Quan for feedback. 
[1] M.W. Apple, Ideology and Curriculum (New York, 1990).

[2] L.S. Siskin, in Achievement and attainment: The comprehensive high school and the problem of reform, edited by B. Fuller (Berkeley, CA, 2007). Smith, in Proceedings of the International Conference on Low Temperature Physics, Madison, 1958, edited by C. Brown (University of Wisconsin, Madison, 1958), p. 201.

[3] F. Z. Belgrave and K.W. Allison, African American psychology: From Africa to America (Academic, Thousand Oaks, 2018)

[4] R. Cohen, in Proceedings of the American Anthropological Association, Washington, DC, 1971, edited by C. Brace, G. Gamble, \& J. Bond C. Brown (Anthropological Studies, no., 1971), p. 41-57.

[5] A.W. Boykin, Negro Education 47, 4 (1978). Retrieved 6/2/20 https://www.jstor.org/stable/pdf/2294999.pdf

[6] E.A. Hurley, A.W. Boykin, and B.A. Allen, The Journal of Psychology 139, 6 (2005).

[7] G. Gay, Culturally Responsive Teaching: Theory, Research, and Practice (Teachers College Press, New York, 2000).

[8] A.L. Duckworth, C. Peterson, M.D. Matthews, and D.R. Kelly, Journal of Personality and Social Psychology 92, 6 (2007).

[9] E. Bonilla-Silva, Ethnic and Racial Studies 35, 2 (2011). Retrieved https://doi.org/10.1080/01419870.2011.613997

[10] C. Hayes and B. Juarez, Democracy and Education 20, 1 (2012).

[11] C. Wang and M.A. Burris, Health Education and Behavior 24 (1997).

[12] C. Wang, J.L. Cash, and L.S. Powers, Health Promotion Practice 1, 1 (2000).

[13] P. Freire, Pedagogy of the Oppressed (Continuum, New York).

[14] M. Gadotti, New Directions For Evaluation, 155 (2017).

[15] E.J. Ozer, M.L. Ritterman, M.G. Wanis, American Journal of Psychology 46, 1-2 (2010).

[16] E.J. Ozer, Advances in Child Development and Behavior 50 2016).

[17] K.J. Strand et al., Community-based Research and Higher Education: Principles and Practices (Wiley \& Sons, New York, 2003).

[18] Y. Anyon et al., Afterschool Matters 27 (2018).

[19] L. T. S. Marsh, Success at a Price: Exploring How a NoExcuses Charter School's Philosophies about Success Inform the Everyday Practices of Teachers and Its Implications on Working-Class Students and Their Caregivers [Unpublished Dissertation] (2017).

[20] M. Davis and B. Heller, Education Next 17, 1 (2017).

[21] S. Dynarski, New York Times (2015). Retrieved 4/15/16 http://www.nytimes.com/2015/11/22/upshot/a-suburbanurban-divide-in-charter-school-success-rates.html? $\mathrm{r}=0$

[22] J. Ladner, Tomorrow's Tomorrow: The Black Woman (Garden City, New York, 1971).

[23] T.J. Yosso, Race, Ethnicity, and Education 8, 1 (2005).

[24] Northeastern City Department of Education, (2016).

[25] E.L. Deci and R. M. Ryan, Psychological Inquiry, 11, 4 (2000).

[26] S. McAlister, "Upgrades" for Youth Leaders: Coro New York Leadership Center's Supports for Youth Leadership Councils in New York City (2017).
[27] N. González, L. Moll. And C. Amanti, Funds of Knowledge: Theorizing Practices in Households, Communities, and Classrooms (Routledge, New Jersey, 2006).

[28] L. T. S. Marsh, Critical Issues in Education 2, 2 (2018). 